\title{
SIMPLE METHOD TO ESTIMATE CELL WALL EXTENSIBILITY COEFFICIENT BY USING ONLY TWO CARDINAL NUMBERS
}

\author{
MARIUSZ PIETRUSZKA \\ Department of Plant Physiology, \\ Faculty of Biology and Environmental Protection University of Silesia \\ Jagiellońska 28, 40-032 Katowice, Poland \\ e-mail: mariusz.pietruszka@us.edu.pl
}

(Received: January 14, 2009. Accepted: June 5, 2009)

\begin{abstract}
In this short communication we consider the extensibility properties of the cell wall. This is accomplished by a heuristically motivated equation for the expanding volume of the cell. The experimentally determined characteristic time $t_{0}$ and temperature $T_{0}$ are the only numbers required for evaluating the effective yielding coefficient $\Phi(t, T)$ in the respective time and temperature domains.
\end{abstract}

KEY WORDS: cell wall, dynamic extensibility coefficient, temperature.

\section{INTRODUCTION}

Growing plant cells are surrounded by a polysacchariderich primary wall that defines cell shape and permits high turgor pressure to develop (Cosgrove 2005, see for a review). These walls must expand to enlarge and keep the wall strong enough to withstand the mechanical stress arising from internal hydrostatic pressure. Cell expansion is merely limited and regulated by the ability of the cell wall to increase in surface area. This constraint from the physical point of view can be reflected by the effective yield rate coefficient $\Phi$. To form the model Ansatz two empirical facts are taken into account: 1) sigmoid character of growth curve in the course of time; 2) absorption character of growth plot in function of temperature.

In plant physiology growth is described by the law of great growth. There also exist agreement that the sigmoid function, as having a non-negative first derivative in positive domain and exactly one inflection point, properly reproduces the large-scale time evolution. In fact, growth of any plant organ can be split into three basic phases: the initial phase of slow growth, the intense growth phase and, eventually, the final phase of slow growth. Such regularity can be represented by a sigmoid curve that characterizes the time course of individual cell growth and the growth of plant organs as a whole (Fogg 1975). The sigmoid function may be analytically expressed by

$$
\mathrm{f}(\mathrm{t})=\frac{1}{2}\left[1+\tanh \left(\left(\mathrm{t}-\mathrm{t}_{0}\right) / 2 / \mathrm{t}_{0}\right]\right.
$$

where $\mathrm{t}_{0}$ denotes the inflection time.
Moreover, experiments suggest (Lewicka and Pietruszka 2008) that in a wide range of about $5-40^{\circ} \mathrm{C}$, elongation, as function of temperature, can be adequately described by the normal distribution (in the non-membrane leakage regime). From the extensive argumentation based on specific measurements for mono- and dicotyledones and the reasoning concerning the central limit theorem (ibid.) it follows that the application of a Gaussian function $\mathrm{g}(\mathrm{T})=\exp [-((\mathrm{T}-$ $\left.\left.\left.-\mathrm{T}_{0}\right) / \mathrm{T}_{0}\right)^{2}\right]$ ) can be empirically and theoretically justified. Also single cell measurements (Lewicka, Ph.D. thesis) on internode of Nitellopsis obtusa L. revealed the same regularity (symmetric Gaussian, or even Lorentzian reflecting the sharp absorption character of this process), as it was observed for monocotyledons and dicotyledones.

\section{Theory}

Taking into consideration the above arguments we may postulate that the volumetric cell extension is governed by $\mathrm{f}$ and $\mathrm{g}$ functions and satisfies the relation

$$
V(t, T)=V_{i} f(t) g(T)
$$

where $V_{i}$ indicates the initial volume at a time $\mathrm{t}=\mathrm{t}_{\mathrm{i}}$. Calculating the time derivative of Eq. (1) and assuming the validity of the Lockhart (1965) equation within the linear approximation, also for $\Phi$ as time and temperature dependent $\Phi=\Phi(t, T)$, we receive the following set of time differential equations

$$
\left\{\begin{array}{l}
\frac{1}{V_{i}} \frac{d V}{d t}=\frac{d f(t)}{d t} g(T)+f(t) \frac{d g(T)}{d t} \\
\frac{1}{V_{i}} \frac{d V}{d t}=\Phi(P-Y)
\end{array}\right.
$$



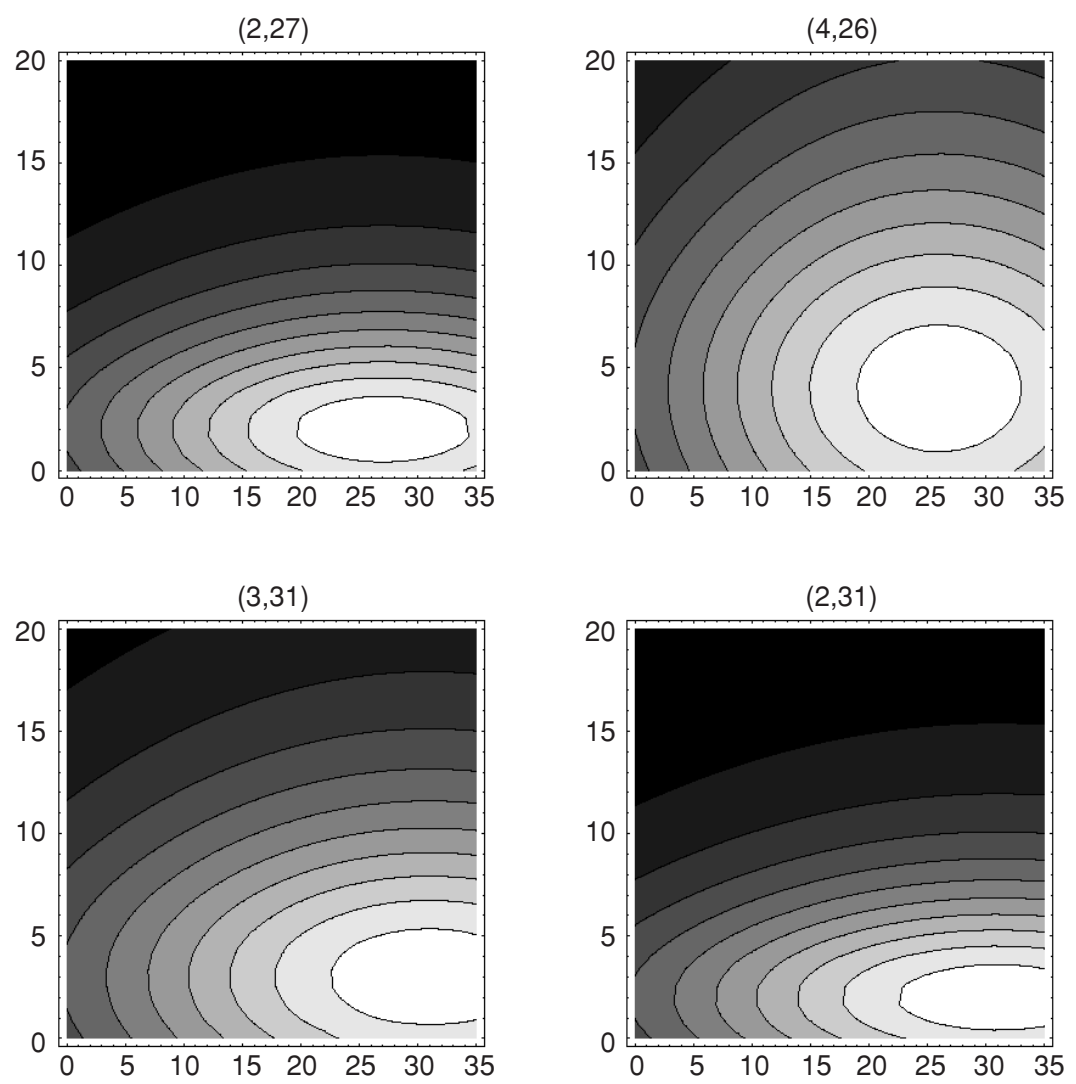

Fig. 1. The calculated through Eq. (3) contour plot of the cell wall yielding coefficient $\Phi$ for maize (Zea mays L.) - the parameters equal to: $\mathrm{t}_{0}=2 \mathrm{~h}, \mathrm{~T}_{0}=27^{\circ} \mathrm{C}$; for internode single cells of Nitellopsis obtusa $\mathrm{L} . \mathrm{t}_{0}=4 \mathrm{~h}$, $\mathrm{T}_{0}=26^{\circ} \mathrm{C}$; for barlow (Hordeum vulgare $\mathrm{L}$.) (APW): $\mathrm{t}_{0}=3 \mathrm{~h}, \mathrm{~T}_{0}=31^{\circ} \mathrm{C}$ and $(\mathrm{APW}+\mathrm{IAA})$ : $\mathrm{t}_{0}=2 \mathrm{~h}, \mathrm{~T}_{0}=31^{\circ} \mathrm{C}$. The horizontal scale denotes temperature in degrees Celsius, while the vertical one - the time in hours. where $\mathrm{P}$ denotes the turgor pressure and $\mathrm{Y}$ the critical turgor. By comparing the latter two equations and calculating the derivative f'(t), we eventually arrive at the explicit expression for the extensibility coefficient (the second term in Eq. (2) vanishes)

$$
\Phi(t, T)=\frac{1}{4 t_{0} G}\left[\operatorname{sech}^{2}\left(\frac{t-t_{0}}{2 t_{0}}\right) e^{-\left(\frac{T-T_{0}}{T_{0}}\right)^{2}}\right]
$$

where $\mathrm{G}=\mathrm{P}-\mathrm{Y}$, in the framework of this approach, must be a constant and $[\Phi]=\mathrm{MPa}^{-1} \mathrm{~h}^{-1}$. Here we put $\mathrm{P}-\mathrm{Y}=\mathrm{const}(\mathrm{t})$, since we assume a constant water intake. In consequence, the internal pressure difference $\mathrm{G}$ is a number, which is typically between 0.3 and 1.0 megapascals (Taiz and Zeiger 2006). The characteristic time $t_{0}$ in Eq. (3) can be read off from experiment at the inflection point $\mathrm{t}=\mathrm{t}_{0}$ of the growth curve (which is identical to the time of the maximum expansion rate). The optimal growth temperature $\mathrm{T}_{0}$ can be, in turn, easily retrieved from measurements.

\section{DISCUSSION}

First we notice that in the original Lockhart's equation the coefficient $\Phi$ is independent of time and temperature. However it turns out, the extensibility coefficient $\Phi$, decisive for the mechanical properties during growth, depends strongly on time (cf. e.g. Liu et al. 2007; Fig. 1A) and temperature (Nakamura et al. 2002; Figs 1, 2 therein). Therefo- re, Eq. (3) can be recognized as a simple tool for rough estimation of the behavior of $\Phi$ in a broad range of time and temperature (the applicability at high temperature end is, however, limited). Nonetheless, presented in this paper simple derivation ends up with a formula for the time and temperature dependent effective yielding coefficient $\Phi$ as expressed by Eq. (3). The preliminary results of the presented new method are collected in Figure 1 in the form of contour plots.

\section{LITERATURE CITED}

COSGROVE D.J. 2005. Growth of the plant cell wall. Nature Rev. Mol. Cell. Biol. 6: 850-861.

FOGG G.E. 1975. The growth of plants. Richard Clay (The Chaucer Press), Bungay, Suffolk, UK.

LEWICKA S., PIETRUSZKA M. 2008. Central limit theorem and the short-term temperature response of coleoptile and hypocotyl elongation growth, Acta Soc. Bot. Pol. 77: 289-292.

LEWICKA S. 2008. Thermodynamic and geometry-dynamic aspects of plant growth. Ph.D. thesis, University of Silesia.

LIU H.-F., GENARD M., GUICHARD S., BERTIN N. 2007. Model-assisted analysis of tomato fruit growth in relation to carbon and water fluxes. J. Exp. Bot. 58: 3567-3580.

LOCKHART A. 1965. An analysis of irreversible plant cell elongation. J. Theor. Biol. 8: 264-275.

NAKAMURA Y., WAKABAYASHI K., KAMISAKA S., TAKAYUKI H. 2002. Effects of temperature on the cell wall and osmotic properties in dark-grown rice and azuki been seedlings. J. Plant Res. 115: 455-461.

TAIZ L., ZEIGER E. 2006. Plant physiology, p. 368, Sinauer Associates, Inc., Publishers. 